\title{
Variation Among Hospitals in the Continuity of Care for Older Hospitalized Patients: a Cross-sectional Cohort Study
}

James S. Goodwin ( $\sim$ jsgoodwi@utmb.edu )

The University of Texas Medical Branch at Galveston

Shuang Li

The University of Texas Medical Branch at Galveston

Jie Zhou

The University of Texas Medical Branch at Galveston

Yong-Fang Kuo

The University of Texas Medical Branch at Galveston

Ann Nattinger

University of Wisconsin-Milwaukee

\section{Research Article}

Keywords: hospitalist, hospital admission, Medicare, continuity of care

Posted Date: March 22nd, 2021

DOI: https://doi.org/10.21203/rs.3.rs-334353/v1

License: (c) (1) This work is licensed under a Creative Commons Attribution 4.0 International License. Read Full License 


\section{Abstract}

Background: Little is known about how continuity of care for hospitalized patients varies among hospitals. We describe the number of different general internal medicine physicians seeing hospitalized patients during a medical admission and how that varies by hospital.

Methods: We conducted a retrospective study of a national $20 \%$ sample of Medicare inpatients from 01/01/16 to 12/31/18. In patients with routine medical admissions (length of stay of 3-6 days, no Intensive Care Unit stay, and seen by only one generalist per day), we assessed odds of receiving all generalist care from one generalist. We calculated rates for each hospital, adjusting for patient and hospital characteristics in a multi-level logistic regression model.

Results: Among routine medical admissions with 3- to 6-day stays, only $43.1 \%$ received all their generalist care from the same physician. In those with a 3-day stay, $50.1 \%$ had one generalist providing care vs. $30.8 \%$ in those with a 6-day stay. In a two-level (admission and hospital) logistic regression model controlling for patient characteristics and length of stay, the odds of seeing just one generalist did not vary greatly by patient characteristics such as age, race/ethnicity, comorbidity or reason for admission. There were large variations in continuity of care among different hospitals and geographic areas. In the highest decile of hospitals, the adjusted mean percentage of patients receiving all generalist care from one physician was $>84.1 \%$, vs. $<24.1 \%$ in the lowest decile. This large degree of variation persisted when hospitals were stratified by size, ownership, location or teaching status.

Conclusions: Continuity of care provided by generalist physicians to medical inpatients varies widely among hospitals. The impact of this variation on quality of care is unknown.

\section{Introduction}

Provider continuity is an important aspect of medical care, associated with better health, fewer hospitalizations, higher quality of life and other important health outcomes [1-10]. Continuity of care can be important both in outpatient care and across community to hospital transitions. By 2006, most hospitalized Medicare patients did not receive any care from a physician who had previously provided care for them [7], and such discontinuity is associated with worse outcomes [8, 9].

Continuity of the care provided to hospitalized patients has been less well studied [10]. Recent studies have suggested that patients admitted for medical illness are likely to be cared for by more than one general internist during their stay [11]. Such discontinuity seems driven by the growth of care by hospitalists, and the fact that many hospitalists have work schedules that do not allow for continuity of care [11]. Just as with outpatient medicine, hospitalized patients who experience discontinuities in their care also have worse outcomes [12].

In this report, we analyze continuity of care in older patients hospitalized for a medical diagnosis, using a $20 \%$ sample of national Medicare data from 2016 to 2018 . We calculate the number of different 
generalist physicians providing care for a patient, and how that varies by length of stay and patient characteristics. We also present the variation among hospitals and among hospital referral regions (HRRs) in the average number of different generalist physicians providing care, adjusted for length of stay, admitting diagnosis and other patient characteristics. We hypothesized that inpatient continuity would decline over time, that it would be only weakly related to patient characteristics such as age, sex, and race/ethnicity, but vary widely among hospitals and by type of hospital.

\section{Methods}

\section{Data Sources}

We used 20\% national Medicare claims for January 1, 2016 through December 31, 2018 in the analyses, including the Medicare Denominator File, the Carrier File, the Outpatient Statistical Analysis File, and the Medicare Provider Analysis and Review File.

\section{Study Population}

The cohorts are presented in Supplementary eFigure 1. We first identified all hospital admissions discharged alive from January 1, 2016 to December 31, 2018 who received care from at least one generalist physician (general internal medicine, family medicine, geriatrics, hospitalist). To reduce heterogeneity, we restricted the cohort to those with a 3-, 4-, 5- or 6-day length of stay. To allow for a year of data prior to admission to assess comorbidity, we included only hospitalizations for enrollees aged 66 + years with a medical diagnostic-related group (DRG) code. We also eliminated admissions with an Intensive Care Unit (ICU) stay and excluded those hospitalizations that were billed for generalist physician services more than once during any day, because both are associated with greater illness severity which might lead to care from different generalist physicians (e.g., an on-call hospitalist at night). We refer to these included admissions as "routine medical admissions." To ensure complete information on comorbidity, we restricted the sample to those with Parts A and B Medicare without a health maintenance organization enrollment in the 12 months prior to the hospitalization, in order to be able to capture diagnoses in the prior year.

\section{Admission characteristics}

The Medicare Denominator File was used to extract information on patient age, sex and race/ethnicity (non-Hispanic white, non-Hispanic black, Hispanic, other). Medicaid eligibility was measured using the state buy-in information in the Medicare Denominator File. The percentage of high school graduates in the patients' ZIP Code area was obtained from the 2017 American Community Survey estimates of the US Census Bureau. Elixhauser comorbidities were assessed based on outpatient, inpatient and carrier claims in the 12 months prior to the hospital admission [13]. Medicare Provider Analysis and Review claims were used to determine the length of stay, DRG, ICU utilization, residence prior to hospitalization (community vs. nursing facility/institution), emergency hospitalization, weekend hospitalization and the number of hospitalizations in the prior 12 months. 


\section{Hospital Characteristics}

Information on hospital bed size, location (urban/rural), type (for profit, nonprofit, public) and medical school affiliation (major, limited, graduate, no affiliation) was extracted from the Provider of Service files [14]. The percentage of Medicaid admissions was calculated from cohort selection step 3 in Supplementary eFigure 1.

\section{Analyses}

We described the number of different generalist physicians submitting evaluation and management charges for a patient during an admission, stratified by length of stay. We then constructed multilevel logistic regression models to generate odds of receiving care from just one generalist physician, adjusted for patient characteristics and length of stay. One model included admission and hospital levels. With this model, we assessed the association of hospital characteristics with the odds of receiving continuity of care. Another model included admission and HRR. We calculated intraclass correlation coefficients (ICCs) from the null models and in models including admission and hospital characteristics, and graphed the adjusted percentage for each hospital or for each HRR of medical admissions receiving care from only one generalist, adjusted for admission characteristics and length of stay. All analyses were performed using SAS version 9.4 (SAS Institute, Cary, NC).

\section{Results}

Table 1 presents the number of medical admissions among Medicare enrollees age 66 or older with a 3-, 4-, 5- or 6-day length of stay stratified by how many different generalists submitted charges for their inpatient care. This was limited to admissions with no ICU stay and where there was a maximum of one generalist charge per day. Overall, $43.1 \%$ of admissions received care from only one generalist, with $15.7 \%$ receiving care from three or more generalists during their stay. The percentage of admissions seeing only one generalist declined substantially with increasing length of stay, from $50.1 \%$ for a 3-day stay to $30.8 \%$ for a 6 -day stay. 
Table 1

Number and percentage of Medical admissions receiving care from 1, 2, or 3 + generalist physicians. Results are stratified by different lengths of stay, from a $20 \%$ sample of US fee-for-service Medicare enrollees from $1 / 1 / 16$ to $12 / 31 / 18$. The cohort is limited to admissions with a medical Diagnostic Related Group admission, with no Intensive Care Unit stay and excluding those receiving any care from generalist physicians twice in one day. Generalist physicians include general internal medicine, family medicine or geriatrics.

\begin{tabular}{|lllll|}
\hline \multirow{2}{*}{$\begin{array}{l}\text { Length of } \\
\text { stay }\end{array}$} & $\begin{array}{l}\text { Number of } \\
\text { hospitalizations }\end{array}$ & \multicolumn{2}{l|}{ Number of generalists } \\
\cline { 3 - 5 } & $\mathbf{N = 1}$ & $\mathbf{N = 2}$ & $\mathbf{N = 3 +}$ \\
\hline $\mathbf{3}$ days & 315,555 & $158,166(50.1 \%)$ & $\begin{array}{l}127,372 \\
(40.4 \%)\end{array}$ & $30,017(9.5 \%)$ \\
\hline $\mathbf{4}$ days & 202,754 & $85,037(41.9 \%)$ & $85,105(42.0 \%)$ & $32,612(16.1 \%)$ \\
\hline $\mathbf{5}$ days & 127,899 & $45,416(35.5 \%)$ & $53,717(42.0 \%)$ & $28,766(22.5 \%)$ \\
\hline $\mathbf{6}$ days & 83,209 & $25,596(30.8 \%)$ & $34,322(41.2 \%)$ & $23,291(28.0 \%)$ \\
\hline Total & 729,417 & $314,215(43.1 \%)$ & $\begin{array}{l}300,516 \\
(41.2 \%)\end{array}$ & $\begin{array}{l}114,686 \\
(15.7 \%)\end{array}$ \\
\hline
\end{tabular}

Table 2 presents the unadjusted rates of seeing just one generalist during a routine medical admission, by admission characteristics. Also shown are the odds of seeing just one generalist, adjusted for other admission characteristics and also for clustering of admissions in hospitals, in a multilevel multiple logistic regression model (Model 1 in Table 2). In both unadjusted and adjusted analyses, there was a strong relationship with length of stay, with 6-day admissions only $38 \%$ as likely as 3-day admissions to receive care from just one generalist (Odds Ratio $[\mathrm{OR}=0.38,95 \%$ Confidence Interval $[\mathrm{Cl}]=0.38,0.39$ ). Admissions from nursing facilities were less likely to see just one generalist $(\mathrm{OR}=0.94 \mathrm{Cl}, 95 \% \mathrm{Cl}=0.92$, $0.96)$, as were admissions from the emergency room $(\mathrm{OR}=0.77 ; 0.75,0.78)$ or those on weekends $(\mathrm{OR}=$ $0.73 ; 0.73,0.74)$. There was very little influence of other patient characteristics, with the odds of seeing only one generalist varying only minimally by age, gender, race/ethnicity, education, Medicaid eligibility or number of prior hospitalizations. We also included the DRG-Major Diagnostic Category and individual patient comorbidities in this model, and they are shown in Supplementary eTable 2 . The differences in odds of receiving care from one generalist by any pre-existing comorbidity were not large. There was some variation by DRG-Major Diagnostic Category, with admissions for mental disorders and burns more likely to be cared for by just one generalist. Odds of seeing just one generalist declined from 2016 to 2018. 
Table 2

Odds of receiving care from only one generalist physician. Results are for admissions aged $66+$ without an Intensive Care Unit stay during hospitalization, adjusted for patient characteristics, from a two level logistic regression model (hospital and admission), among a 20\% sample of US fee-for-service Medicare enrollees age $\geq 66$ years, from $1 / 1 / 16$ to $12 / 31 / 18$.

\begin{tabular}{|c|c|c|c|c|}
\hline Characteristic & $\mathbf{N}(\%)$ & $\begin{array}{l}\text { Observed } \\
\text { rate }\end{array}$ & $\begin{array}{l}\text { Model } 1 \\
\text { Odds Ratio* (95\% } \\
\text { Confidence Interval) }\end{array}$ & $\begin{array}{l}\text { Model } 2 \\
\text { Odds Ratio* }(95 \% \\
\text { Confidence Interv }\end{array}$ \\
\hline All & 729,417 & $43.1 \%$ & & \\
\hline \multicolumn{5}{|l|}{ Age (Per year) } \\
\hline $\begin{array}{l}\text { Q1 (> = 66; } \\
<=73)\end{array}$ & $\begin{array}{l}188,231 \\
(25.8 \%)\end{array}$ & $42.8 \%$ & Reference & Reference \\
\hline $\begin{array}{l}\mathrm{Q} 2(>=74 ; \\
<=80)\end{array}$ & $\begin{array}{l}182,726 \\
(25.1 \%)\end{array}$ & $43.1 \%$ & $1.00(0.99-1.02)$ & $1.00(0.99-1.02)$ \\
\hline $\begin{array}{l}\text { Q3 (>=81; } \\
<=87)\end{array}$ & $\begin{array}{l}189,102 \\
(25.9 \%)\end{array}$ & $43.1 \%$ & $1.01(0.99-1.03)$ & $1.01(0.99-1.03)$ \\
\hline Q4 (> = 87) & $\begin{array}{l}169,358 \\
(23.2 \%)\end{array}$ & $43.3 \%$ & $1.03(1.01-1.05)$ & $1.03(1.01-1.04)$ \\
\hline
\end{tabular}

Education (Percent of persons age $25+$ in Zip area with high school education) (per percent)

$\begin{array}{lllll}\text { Q1 }(<=82.8) & \begin{array}{l}183,360 \\ (25.1 \%)\end{array} & 48.2 \% & \text { Reference } & \text { Reference } \\ \begin{array}{l}\text { Q2 }(>=82.9 ; \\ <=88.7)\end{array} & \begin{array}{l}182,269 \\ (25.0 \%)\end{array} & 44.0 \% & 0.99(0.98-1.01) & 0.99(0.98-1.01) \\ \begin{array}{l}\text { Q3 }(>=88.8 ; \\ <=93.0)\end{array} & \begin{array}{l}183,500 \\ (25.2 \%)\end{array} & 41.1 \% & 0.97(0.96-0.99) & 0.98(0.96-0.99) \\ \text { Q4 (>=93.1) } & \begin{array}{l}180,288 \\ (24.7 \%)\end{array} & 38.9 \% & 0.98(0.96-0.99) & 0.98(0.97-1.01)\end{array}$

Year

2016 239,223

44.4\% Reference

Reference

(32.8\%)

2017

247,960

(34.0\%)

$43.1 \%$

$0.96(0.95-0.97)$

$0.96(0.95-0.97)$

2018

242,234

(33.2\%)

$41.7 \%$

$0.91(0.90-0.92)$

$0.91(0.90-0.92)$

Gender

a Odds ratio are from multilevel model (admission and hospital) adjusted for all characteristics presented in the table, as well as the 31 Elixhauser comorbidities (each entered separately), and the Diagnosis Related Group-Major Diagnostic Category (DRG-MDC) codes. Results for the comorbidities and DRG-MDC are presented in Supplementary eTable 1. 


\begin{tabular}{|c|c|c|c|c|}
\hline Characteristic & $\mathrm{N}(\%)$ & $\begin{array}{l}\text { Observed } \\
\text { rate }\end{array}$ & $\begin{array}{l}\text { Model } 1 \\
\text { Odds Ratio* (95\% } \\
\text { Confidence Interval) }\end{array}$ & $\begin{array}{l}\text { Model } 2 \\
\text { Odds Ratio* (95\% } \\
\text { Confidence Interval) }\end{array}$ \\
\hline Female & $\begin{array}{l}440,343 \\
(60.4 \%)\end{array}$ & $43.5 \%$ & Reference & Reference \\
\hline Male & $\begin{array}{l}289,074 \\
(39.6 \%)\end{array}$ & $42.5 \%$ & $1.01(1.01-1.02)$ & $1.01(1.01-1.02)$ \\
\hline \multicolumn{5}{|l|}{ Medicaid } \\
\hline No & $\begin{array}{l}570,166 \\
(78.2 \%)\end{array}$ & $42.3 \%$ & Reference & Reference \\
\hline Yes & $\begin{array}{l}159,251 \\
(21.8 \%)\end{array}$ & $46.0 \%$ & $1.01(0.99-1.03)$ & $1.01(0.99-1.03)$ \\
\hline \multicolumn{5}{|l|}{ Race } \\
\hline White & $\begin{array}{l}612,701 \\
(84.0 \%)\end{array}$ & $42.3 \%$ & Reference & Reference \\
\hline Black & $\begin{array}{l}64,030 \\
(8.8 \%)\end{array}$ & $46.4 \%$ & $1.03(1.01-1.05)$ & $1.03(1.01-1.05)$ \\
\hline Hispanic & $\begin{array}{l}30,267 \\
(4.1 \%)\end{array}$ & $49.9 \%$ & $0.99(0.96-1.02)$ & $0.99(0.97-1.02)$ \\
\hline Other & $\begin{array}{l}22,419 \\
(3.1 \%)\end{array}$ & $45.0 \%$ & $1.02(0.98-1.05)$ & $1.02(0.99-1.05)$ \\
\hline \multicolumn{5}{|c|}{$\begin{array}{l}\text { Residence prior to } \\
\text { hospitalization }\end{array}$} \\
\hline Community & $\begin{array}{l}667,721 \\
(91.5 \%)\end{array}$ & $43.2 \%$ & Reference & Reference \\
\hline $\begin{array}{l}\text { Nursing } \\
\text { facility or } \\
\text { other } \\
\text { institution }\end{array}$ & $\begin{array}{l}61,696 \\
(8.5 \%)\end{array}$ & $42.1 \%$ & $0.94(0.92-0.96)$ & $0.94(0.92-0.96)$ \\
\hline \multicolumn{5}{|l|}{$\begin{array}{l}\text { Length of } \\
\text { stay }\end{array}$} \\
\hline 3 days & $\begin{array}{l}315,555 \\
(43.2 \%)\end{array}$ & $50.1 \%$ & Reference & Reference \\
\hline
\end{tabular}

\footnotetext{
${ }^{a}$ Odds ratio are from multilevel model (admission and hospital) adjusted for all characteristics presented in the table, as well as the 31 Elixhauser comorbidities (each entered separately), and the Diagnosis Related Group-Major Diagnostic Category (DRG-MDC) codes. Results for the comorbidities and DRG-MDC are presented in Supplementary eTable 1.
} 


\begin{tabular}{|c|c|c|c|c|}
\hline Characteristic & $N(\%)$ & $\begin{array}{l}\text { Observed } \\
\text { rate }\end{array}$ & $\begin{array}{l}\text { Model } 1 \\
\text { Odds Ratio* (95\% } \\
\text { Confidence Interval) }\end{array}$ & $\begin{array}{l}\text { Model } 2 \\
\text { Odds Ratio* (95\% } \\
\text { Confidence Interval) }\end{array}$ \\
\hline 4 days & $\begin{array}{l}202,754 \\
(27.8 \%)\end{array}$ & $41.9 \%$ & $0.68(0.67-0.69)$ & $0.68(0.67-0.69)$ \\
\hline 5 days & $\begin{array}{l}127,899 \\
(17.5 \%)\end{array}$ & $35.5 \%$ & $0.49(0.48-0.50)$ & $0.50(0.49-0.50)$ \\
\hline 6 days & $\begin{array}{l}83,209 \\
(11.4 \%)\end{array}$ & $30.8 \%$ & $0.38(0.38-0.39)$ & $0.39(0.38-0.39)$ \\
\hline \multicolumn{5}{|c|}{ Number of hospitalizations in 12 months before admission (per hospitalization) } \\
\hline 0 & $\begin{array}{l}335,465 \\
(46.0 \%)\end{array}$ & $42.8 \%$ & Reference & Reference \\
\hline 1 & $\begin{array}{l}186,403 \\
(25.6 \%)\end{array}$ & $42.8 \%$ & $1.01(0.99-1.02)$ & $1.01(0.99-1.02)$ \\
\hline 2 and 3 & $\begin{array}{l}147,014 \\
(20.2 \%)\end{array}$ & $43.5 \%$ & $1.03(1.02-1.05)$ & $1.03(1.02-1.05)$ \\
\hline 4 and above & $\begin{array}{l}60,535 \\
(8.3 \%)\end{array}$ & $44.3 \%$ & $1.05(1.02-1.07)$ & $1.05(1.02-1.07)$ \\
\hline \multicolumn{5}{|c|}{ Emergency hospitalization } \\
\hline No & $\begin{array}{l}143,678 \\
(19.7 \%)\end{array}$ & $50.0 \%$ & Reference & Reference \\
\hline Yes & $\begin{array}{l}585,739 \\
(80.3 \%)\end{array}$ & $41.4 \%$ & $0.77(0.75-0.78)$ & $0.77(0.76-0.79)$ \\
\hline \multicolumn{5}{|c|}{ Weekend hospitalization } \\
\hline No & $\begin{array}{l}505,956 \\
(69.4 \%)\end{array}$ & $45.2 \%$ & Reference & Reference \\
\hline Yes & $\begin{array}{l}223,461 \\
(30.6 \%)\end{array}$ & $38.3 \%$ & $0.73(0.73-0.74)$ & $0.73(0.73-0.74)$ \\
\hline \multicolumn{5}{|l|}{ Bed size } \\
\hline$>500$ & $\begin{array}{l}169,656 \\
(23.3 \%)\end{array}$ & $39.9 \%$ & - & Reference \\
\hline $201-500$ & $\begin{array}{l}314,367 \\
(43.1 \%)\end{array}$ & $40.5 \%$ & - & $1.04(0.91-1.20)$ \\
\hline
\end{tabular}

\footnotetext{
${ }^{a}$ Odds ratio are from multilevel model (admission and hospital) adjusted for all characteristics presented in the table, as well as the 31 Elixhauser comorbidities (each entered separately), and the Diagnosis Related Group-Major Diagnostic Category (DRG-MDC) codes. Results for the comorbidities and DRG-MDC are presented in Supplementary eTable 1.
} 


\begin{tabular}{|c|c|c|c|c|}
\hline Characteristic & $N(\%)$ & $\begin{array}{l}\text { Observed } \\
\text { rate }\end{array}$ & $\begin{array}{l}\text { Model } 1 \\
\text { Odds Ratio* (95\% } \\
\text { Confidence Interval) }\end{array}$ & $\begin{array}{l}\text { Model } 2 \\
\text { Odds Ratio* }(95 \% \\
\text { Confidence Interval) }\end{array}$ \\
\hline$<=200$ & $\begin{array}{l}245,394 \\
(33.6 \%)\end{array}$ & $48.6 \%$ & - & $1.37(1.19-1.58)$ \\
\hline \multicolumn{5}{|l|}{ Location } \\
\hline Rural & $\begin{array}{l}138,481 \\
(19.0 \%)\end{array}$ & $53.1 \%$ & - & Reference \\
\hline Urban & $\begin{array}{l}590,936 \\
(81.0 \%)\end{array}$ & $40.7 \%$ & - & $0.64(0.59-0.70)$ \\
\hline \multicolumn{5}{|l|}{$\begin{array}{l}\text { Type of } \\
\text { provider }\end{array}$} \\
\hline For profit & $\begin{array}{l}96,302 \\
(13.3 \%)\end{array}$ & $52.1 \%$ & - & Reference \\
\hline Public & $\begin{array}{l}97,306 \\
(13.3 \%)\end{array}$ & $48.3 \%$ & - & $0.82(0.74-0.92)$ \\
\hline Non-profit & $\begin{array}{l}535,809 \\
(73.4 \%)\end{array}$ & $40.5 \%$ & - & $0.54(0.49,0.59)$ \\
\hline \multicolumn{5}{|c|}{ Medical school affiliation } \\
\hline Major & $\begin{array}{l}143,993 \\
(19.7 \%)\end{array}$ & $41.3 \%$ & - & Reference \\
\hline Limited & $\begin{array}{l}144,656 \\
(19.8 \%)\end{array}$ & $40.0 \%$ & - & $0.80(0.69-0.92)$ \\
\hline Graduate & $\begin{array}{l}31,784 \\
(4.4 \%)\end{array}$ & $38.1 \%$ & - & $0.83(0.66,1.04)$ \\
\hline No affiliation & $\begin{array}{l}408,984 \\
(56.1 \%)\end{array}$ & $45.2 \%$ & - & $0.96(0.85,1.10)$ \\
\hline $\begin{array}{l}\text { aodds ratio are } \\
\text { presented in the } \\
\text { Diagnosis Relat } \\
\text { and DRG-MDC }\end{array}$ & $\begin{array}{l}\text { om multil } \\
\text { able, as w } \\
\text { d Group-N } \\
\text { e presente }\end{array}$ & $\begin{array}{l}\text { nodel (adn } \\
\text { s the } 31 \text { Eli } \\
\text { Diagnostic }\end{array}$ & $\begin{array}{l}\text { ission and hospital) a } \\
\text { hauser comorbidities } \\
\text { Category (DRG-MDC) } \\
\text { ary eTable } 1 .\end{array}$ & $\begin{array}{l}\text { for all characteristics } \\
\text { tered separately), and the } \\
\text { esults for the comorbidities }\end{array}$ \\
\hline
\end{tabular}

Model 2 in Table 2 includes specific hospital characteristics in addition to admission characteristics. Hospital characteristics associated with increased odds of continuity of care include smaller size, rural location, for-profit status and major teaching hospital. Including hospital characteristics had minimal effect on the relative lack of association of admission characteristics with the odds of receiving care from just one generalist. 
We estimated the variation among hospitals in continuity of care with ICCs. The ICC for the two-level null model was 0.29 , indicating that $29 \%$ of the variation in whether a hospitalized patient experiences continuity of care is explained by which hospital they are in. It was unchanged when the admission characteristics listed in Table 2 and Supplementary eTable 1 were added (that is, Model 1 of Table 2). When the hospital characteristics listed in Table 2 were added, the ICC decreased to 0.26 , suggesting that about $10 \%$ of the variation among hospitals in continuity of care is explained by those hospital characteristics.

Figure 1 shows the distribution among 4,523 US hospitals of the mean rate of a patient receiving care from just one generalist, adjusted for all the admission characteristics shown in Table 2 and Supplementary eTable 1 . There was substantial variation, with $26.4 \%$ of hospitals having significantly greater continuity ( $79.2 \%$ of admissions seeing only one generalist) and $35.2 \%$ of hospitals having significantly lower continuity (29.6\% of admissions seeing only one generalist). There were also large geographic variations in continuity of care (Fig. 2). The mean adjusted rate of seeing only one hospitalist was $\leq 32 \%$ in the lowest $20 \%$ of HRRs and was $\geq 52 \%$ in the highest $20 \%$. Rates appeared generally lower in New England, the mid-Atlantic states and the Northwest.

Table 3 presents the distributions of adjusted percent of admissions seeing only one generalist among 4,523 US hospitals in the US, stratified by hospital characteristics. In the bottom $10 \%$ of all hospitals, the adjusted percent of routine medical admissions seeing only one generalist was $\leq 24.1 \%$, vs. $>84.1 \%$ for the top $10 \%$ of hospitals. When the hospitals were stratified by size, location, profit status or medical school affiliation, the breadth of the distributions was not largely affected (i.e., the distance between the 10th and 90th percentiles). However, larger hospitals and those with medical school affiliation had somewhat less variation than the comparison categories (Table 3). Supplementary eTable 2 presents the same analyses but limited to the $\mathbf{4 4 2}$ major teaching hospitals. There was still a large degree of variation in inpatient continuity of care when the analysis was limited to large major teaching hospitals. 
Table 3

Distribution of 4,523 US hospitals, stratified by hospital characteristics. Results show the adjusted percent of routine medical admissions who received all of their general medical care from one physician.

$\mathrm{N}$ hospital $\mathrm{N}$ admission (\%) Adjusted percent receiving care by one generalist*

(\%)

\begin{tabular}{|lllllllll} 
Hospital type & & & Mean & 10th & 25th & 50th & 75th & 90th \\
\hline All hospitals & 4,523 & $729,417(100 \%)$ & 52.6 & 24.1 & 34.9 & 51.5 & 69.9 & 84.1
\end{tabular}

\section{Bed size}

\begin{tabular}{lllllllll}
$>500$ & 367 & $169,656(23.3 \%)$ & 42.3 & 21.5 & 28.3 & 42.3 & 54.1 & 64.5 \\
\hline $201-500$ & 1,091 & $314,367(43.1 \%)$ & 44.7 & 21.6 & 29.7 & 43.0 & 57.7 & 71.2 \\
$<=200$ & 3,065 & $245,394(33.6 \%)$ & 57.7 & 26.9 & 39.4 & 57.4 & 77.0 & 88.9
\end{tabular}

\section{Location}

\begin{tabular}{lllllllll} 
Rural & 1,870 & $138,481(19.0 \%)$ & 61.7 & 30.3 & 44.3 & 63.1 & 80.4 & 91.1 \\
\hline Urban & 2,653 & $590,936(81.0 \%)$ & 47.0 & 22.1 & 30.5 & 45.3 & 61.0 & 76.3
\end{tabular}

\section{Type of provider}

\begin{tabular}{|lllllllll} 
For profit & 760 & $96,302(13.3 \%)$ & 59.8 & 29.4 & 44.0 & 59.1 & 77.6 & 88.5 \\
\hline Public & 1,045 & $97,306(13.3 \%)$ & 61.3 & 28.4 & 43.6 & 63.2 & 80.8 & 90.9 \\
\hline Non-profit & 2,718 & $535,809(73.4 \%)$ & 49.4 & 23.6 & 33.1 & 48.0 & 64.5 & 78.7
\end{tabular}

Medical school affiliation

\begin{tabular}{lllllllll} 
Major & 442 & $143,993(19.7 \%)$ & 45.8 & 23.3 & 31.3 & 45.5 & 58.4 & 69.2 \\
\hline Limited & 627 & $144,656(19.8 \%)$ & 45.7 & 22.2 & 29.7 & 42.7 & 59.6 & 75.5 \\
\hline Graduate & 126 & $31,784(4.4 \%)$ & 44.2 & 22.0 & 29.8 & 43.4 & 55.8 & 68.4 \\
\hline No affiliation & 3,328 & $408,984(56.1 \%)$ & 55.3 & 25.0 & 37.0 & 54.6 & 73.9 & 87.1
\end{tabular}

*Adjusted for admission characteristics in a two-level logistic regression model. Admission characteristics are listed in Table 2 and Supplementary eTable 1.

\section{Discussion}

Continuity of care has been threatened by an array of forces for at least two decades. These include the decrease in primary care physicians, changes in health insurance, the growth of specialization and the need to ensure easy and timely access to care [15-18]. Considerable attention has been paid to the discontinuities of care across the community to hospital and back to the community $[1,2,7,9]$. 
Few studies have examined inpatient continuity of care in the hospital. Epstein et al. [19] studied a large national hospitalist group and reported that approximately $60 \%$ of admissions for pneumonia and heart failure saw at least two hospitalists. In a study of Medicare admissions for chronic obstruction pulmonary disease, congestive heart failure and pneumonia, we found that inpatient continuity of care provided by generalist physicians, including hospitalists, non-hospitalist generalists and primary care physicians, declined substantially between 1996 and 2006 [8].

Continuity of care for hospitalized patients is important for several reasons. It is unlikely that all relevant information communicated by patients and their families to a physician is included in the electronic medical record or is transmitted orally during hand-offs. In addition, information relevant to patient values and preferences and degree of family involvement can be key in medical and discharge decision making. Patients and their families may be less comfortable soliciting and following the advice of a physician they are seeing for the first time, particularly if the issue is value-laden such as end of life issues or discharge destination $[4,6,20]$.

Few studies have explored associations of inpatient continuity of care with outcomes. A Joint Commission report blamed miscommunication between physicians during hospital hand-offs for the majority of serious adverse effects [21, 22]. Epstein et al. [19] reported that hospitalist discontinuity was associated with increased length of stay. In a single hospital study, hospitalist discontinuity was associated with a small increase in costs [23]. Another study of 474 admissions to a single hospital found no relationship of discontinuity with adverse events [24]. It is difficult to interpret the results of such studies because of potential biases. For example, hospital complications might lead to discontinuity because of care from an on-call physician and might also lead to increased length of stay and worse outcomes. In a recent study [12], we attempted to control for that bias by assessing the association of the working schedules of hospital physicians with the outcomes of patients under their care. We found that admissions cared for by hospitalists who usually worked several days in a row experienced lower postdischarge mortality, readmissions and costs than did admissions cared for by hospitalists with more intermittent schedules [12].

In the current study, we included medical admissions receiving care from any generalist physician (general internal medicine, family medicine, geriatrics), whether or not they were hospitalists. The diagnoses were predominately respiratory, cardiovascular, renal and gastroenterology (Supplementary eTable 1). We limited the sample to what we termed routine medical admissions, eliminating those with an ICU stay or who had received care from two generalist physicians on the same day, in order to better describe the usual care patterns of patients hospitalized for medical conditions. The variation among hospitals in continuity of care was substantial; in a two-level model, $29 \%$ of the variation in whether admissions were cared for by just one generalist was attributed to which hospital they were in. Conversely, the characteristics of the admission contributed very little to the variation in continuity. Adding admission characteristics did not measurably change the ICC. The 4,523 hospitals in the analyses were highly heterogeneous in size, location, ownership and academic affiliation. However, these 
characteristics explained only about $10 \%$ of the variation among hospitals, and this variation was substantial even after stratifying by hospital type (Table 3).

Limitations of the analyses include their reliance on Medicare fee-for-service data, which excludes older individuals enrolled in Medicare health maintenance organizations. In addition, it is possible that differences in patients among hospitals contributed to the variation in continuity. However, adjusting for age, diagnoses, comorbidity and other factors had very little effect on estimates of continuity.

\section{Conclusions}

In conclusion, there is great variability in the US in the likelihood that hospitalized Medicare patients will receive all their hospital care from one physician, and much of the variation is driven by the hospital to which the patient is admitted. The large degree of variation even among similar types of hospitals, such as major teaching hospitals, suggests that much of the variation in continuity of care is discretionary.

Additional studies should examine the impact of these differences in continuity, if any, on quality of care and outcomes.

\section{Abbreviations}

HRR: Hospital Referral Region

DRG: Diagnosis Related Group

ICU: Intensive Care Unit

Cl: Confidence Interval

OR: odds ratio

ICC: intraclass correlation coefficient

VRDC: Virtual Research Data Center

CMS: Center for Medicare and Medicaid Services

\section{Declarations}

\section{Ethics approval and consent to participate:}

All protocols were carried out in accordance with relevant guidelines and regulations. The University of Texas Medical Branch Institutional Review Board approved the study and waived the requirement for informed consent.

Consent for publication: 
Not applicable.

\section{Availability of data and materials:}

The Medicare datasets used in this study are in the Virtual Research Data Center (VRDC) of the Center for Medicare and Medicaid Services (CMS). The authors analyzed all data within the CMS site and, as part of the Data Use Agreement (DUA), are not allowed to download VRDC data. The datasets used and/or analyzed during the current study are available from CMS after approval of a DUA and payment of a user fee to CMS.

\section{Competing interests:}

The authors state that they have no competing interests.

\section{Funding:}

This work was supported by the National Institutes of Health (R01 AG33134, P30 AG024832, and UL1 TR001439 to JSG). The funders had no role in the design and conduct of the study; collection, management, analysis, and interpretation of the data; preparation, review, or approval of the manuscript; and decision to submit the manuscript for publication.

\section{Author Contributions:}

Study concept and design: JSG and AN. Acquisition of data: JSG, SL. Analysis and interpretation of data: All authors. Preparation of the manuscript: All authors.

\section{Acknowledgements:}

The authors thank Sarah Smith, PhD for editorial assistance with this manuscript.

\section{Impact Statement:}

We certify that this work is novel. This is the first report that continuity of care provided to older individuals hospitalized with a medical illness varies widely among hospitals, even among hospitals of the same size and type.

\section{References}

1. Willett LL, Landefeld CS. The costs and benefits of hospital care by primary physicians: Continuity counts. JAMA Intern Med. 2017;177(12):1788-9.

2. Sharma G, Kuo YF, Freeman JL, Zhang DD, Goodwin JS. Outpatient follow-ups visit and 30-day emergency department visit and readmission in patients hospitalized for chronic obstructive pulmonary disease. Arch Intern Med. 2010;170(18):1664-70. 
3. Chen $\mathrm{HM}, \mathrm{Tu} \mathrm{YH}$, Chen $\mathrm{CM}$. Effect of continuity of care on quality of life in older adults with chronic diseases: a meta-analysis. Clinical Nurs Res. 2017;26(3):266-84.

4. Tammes P, Salisbury C. Continuity of primary care matters and should be protected. BMJ. 2017;356; doi:10.1136/bmj.j373.

5. Nyweide DJ, Anthony DL, Bynum JP, Strawderman RL, Weeks WB, Casalino LP, Fisher ES. Continuity of care and the risk of preventable hospitalization in older adults. JAMA Intern Med. 2013;173(20):1879-85.

6. Sharma G, Freeman JL, Zhang D, Goodwin JS. Continuity of care and ICU utilization during end of life. Arch Intern Med. 2009;169(1):81-6.

7. Sharma G., Fletcher KE, Zhang D, Kuo YF, Freeman JL, Goodwin JS. Continuity of outpatient and inpatient care for hospitalized older adults. JAMA. 2009;301(16):1671-80.

8. Stevens JP, Nyweide DJ, Maresh S, Hatfield LA, Howell MD, Landon BE. Comparison of hospital resource use and outcomes among hospitalists, primary care physicians, and other generalists. JAMA Intern Med. 2017;177(12):1781-7.

9. Kuo YF, Goodwin JS. Association of hospitalist care with medical utilization after discharge: evidence of cost shift from a cohort study. Ann Intern Med. 2011;155(3):152-9.

10. Fletcher KE, Sharma G, Zhang D, Kuo YF, Goodwin JS. Trends in inpatient continuity of care for a cohort of Medicare patients 1996-2006. J Hosp Med. 2011;6(8):438-44.

11. Goodwin JS, Zhou J, Kuo YF, Nattinger AB. Work schedules of hospitalist and continuity of care during hospital stays of Texas Medicare patient: An observational study. J Gen Intern Med. 2019;34(4):489-91.

12. Goodwin JS, Li S, Kuo YF. Association of work schedules of hospitalists with patient outcomes of hospitalization. JAMA Intern Med. 2020;180(2):215-22.

13. Elixhauser A, Steiner C, Harris DR, Coffey RM. Comorbidity measures for use with administrative data. Med Care. 1998;36:8-27.

14. Centers for Medicare \& Medicaid Services (CMS). 2017 Provider of Services Current Files (POS). CMS website. https://www.cms.gov/Research-Statistics-Data-and-Systems/Downloadable-Public-UseFiles/Provider-of-Services/. Accessed 24 Aug 2020.

15. Bodenheimer T, Pham HH. Primary care: Current problems and proposed solutions. Health Aff. 2010;29(5):799-805.

16. Donaldson MS, Yordy KD, Lohr KN, Vanselow NA, eds. Primary Care. America's Health in a New Era. Washington, DC: Institute of Medicine, National Academy of Sciences; 1996;47-9.

17. Haggerty JL, Reid RJ, Freeman GK, Starfield BH, Adair CE, McKendry R. Continuity of care: a multidisciplinary review. BMJ. 2003;327(7425):1219-21.

18. Flock SA, Strange KC, Zyzanski SJ. The impact of insurance type and forced discontinuity on the delivery of primary care. J Fam Pract. 1997;45(2):129-35. 
19. Epstein K, Juarez E, Epstein A, Loya K, Singer A. The impact of fragmentation of hospitalist care on length of stay. J Hosp Med. 2010;5(6):335-8.

20. Wray CM, Farnan JM, Arora VM, Meltzer DO. A qualitative analysis of patients' experience with hospitalist service handovers. J Hosp Med. 2016;11(10):675-81.

21. The Joint Commission Center for Transforming Healthcare Releases Targeted Solutions Tool for Hand-off Communications. 2012. https://www.jointcommission.org/-/media/deprecatedunorganized/imported-assets/tjc/system-folders/blogs/tst_hoc_persp_08_12pdf.pdf? $\mathrm{db}=$ web\&hash=BA7C8CDB4910EF6633F013D0BC08CB1C. Accessed 24 Aug 2020.

22. The Joint Commission. Inadequate hand-off communication. Sentinel Event Alert. 2017;58:1-6. https://www.jointcommission.org/-/media/tjc/documents/resources/patient-safety-topics/sentinelevent/sea_58_hand_off_comms_9_6_17_final_(1).pdf. Accessed 24 Aug 2020.

23. Turner J, Hansen L, Hinami K, Christensen N, Peng J, Lee J, Williams MV, O'Leary KJ. The impact of hospitalist discontinuity on hospital cost, readmissions, and patient satisfaction. J Gen Intern Med. 2014;29(7):1004-8.

24. O'Leary KJ, Turner J, Christensen N, Ma M, Lee J, Williams MV, Hansen LO. The effect of hospitalist discontinuity on adverse events. J Hosp Med. 2015;10(3):147-51.

\section{Figures}

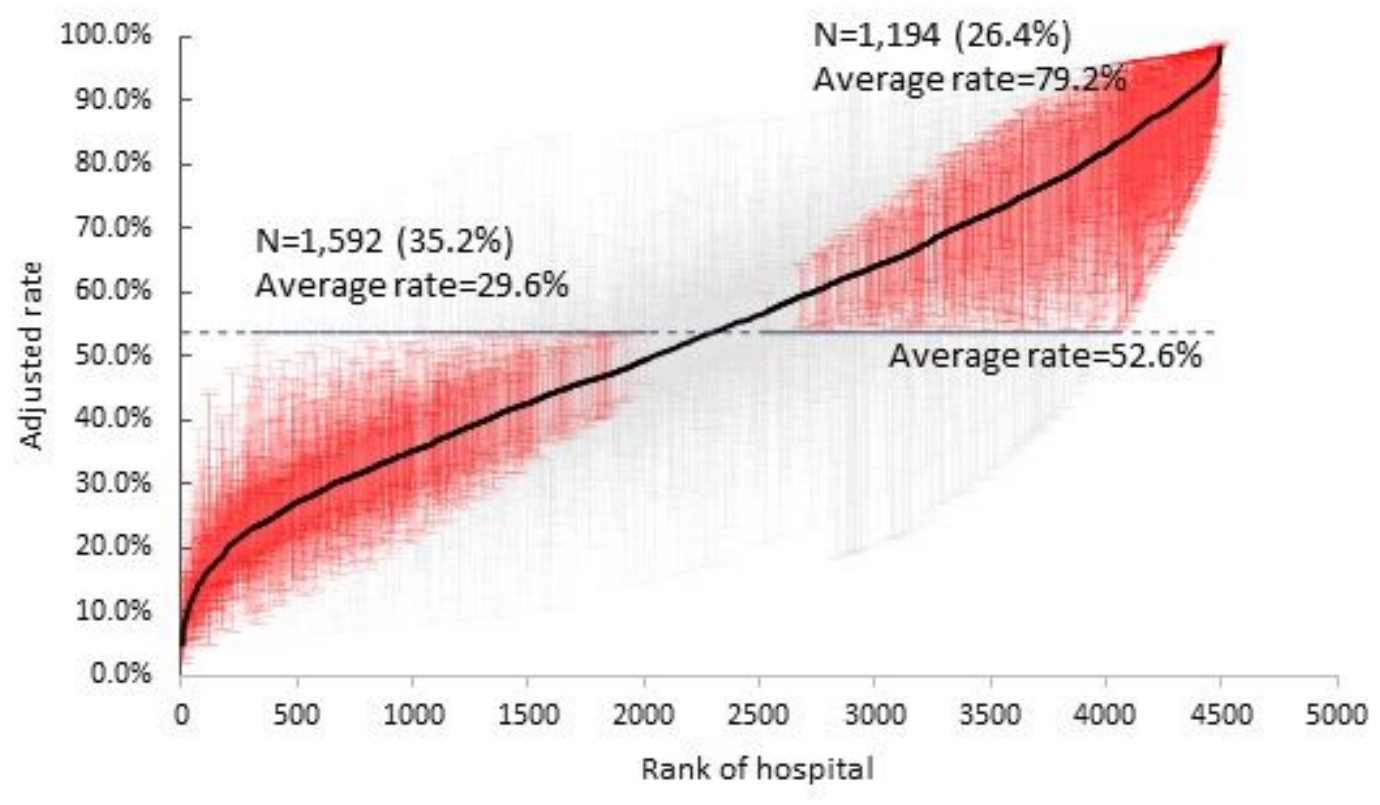

Figure 1 
Adjusted rate of seeing one generalist during hospitalization, by hospital. Adjusted mean rate of seeing only one generalist during hospitalization for 4,523 US hospitals, from a multilevel logistic regression model (admission, hospital) adjusted for the patient characteristics listed in Table 2, plus Diagnosis Related Group-Major Diagnostic Categories (DRG-MDC) and the 31 Elixhauser comorbidities listed in Supplementary eTable 1. Hospitals with adjusted rates significantly different from the mean adjusted rate of all hospitals are shown in red, with the $95 \%$ confidence intervals.

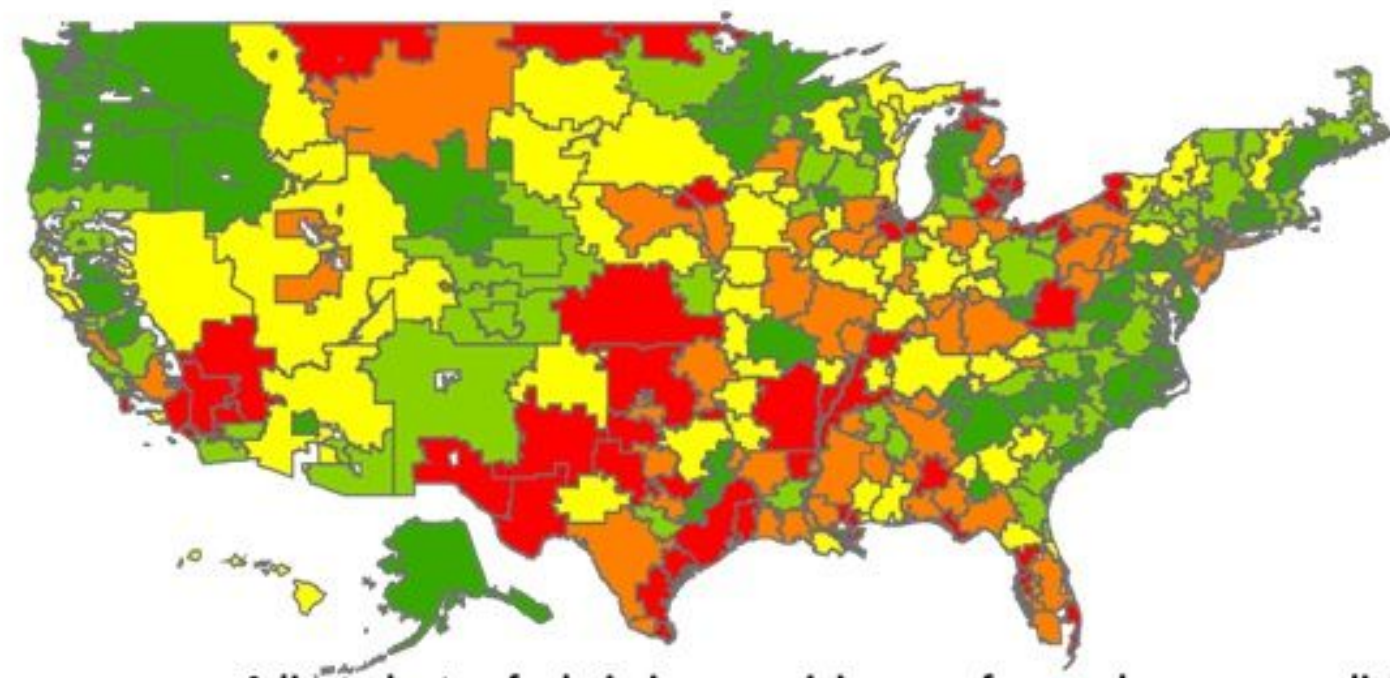

Adjusted rate of admissions receiving care from only one generalist

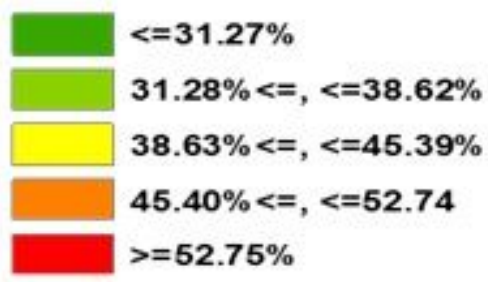

Figure 2

Adjusted rate of seeing one generalist during hospitalization, by Hospital Referral Region (HRR). Adjusted rate of seeing only one generalist during hospitalization, a multilevel logistic regression model (admission, HRR) adjusted for the patient characteristics listed in Table 2, plus Diagnosis Related GroupMajor Diagnostic Categories and the 31 Elixhauser comorbidities listed in Supplementary eTable 1. The HRRs are color coded by the quintile of their adjusted mean rate of admissions seeing just one generalist physician. The intraclass correlation coefficient for the model used to generate the HRR adjusted rates was 0.071 . Note: The designations employed and the presentation of the material on this map do not imply the expression of any opinion whatsoever on the part of Research Square concerning the legal status of any country, territory, city or area or of its authorities, or concerning the delimitation of its frontiers or boundaries. This map has been provided by the authors.

\section{Supplementary Files}


This is a list of supplementary files associated with this preprint. Click to download.

- SupplementaryInformation031621.docx 